time ABPI Code of Practice Committee rulings about complaints are released for general scrutiny so much time will have elapsed from the original alleged breach of practice that there will be little or no consumer interest remaining in this committee's adjudications. Surely, if the $\mathrm{ABPI}$ is to function in the interests of patien care as well as in those of the industry itself, such restraints ought to be removed, so that all rulings and reports on matters concerning medical practice made by the Code of Practice Committee can be made immediately available to the medical profession as well as to the pharmaceutical industry.

\section{Graham Crompton} Northern General Hospital, Edinburgh EH5 2DQ

\section{Earlier help for sick doctors}

SIR,-I was extremely interested in the letter from Dr A Allibone (21 June, p 1540) on the problem of the sick doctor, as must anyone be who has had the privilege and the experience of working in a medical defence organisation The new arrangements for ensuring that any seriously sick doctor who insists on remaining in practice shall be assessed in private by GMC committee with powers to prevent his continuing to do so are welcome as an honourable and humane way of dealing with a difficult but not uncommon situation.

Dr Allibone rightly points out that this, nevertheless, is but the end of a chapter which should ideally be brought to an earlier close. Let us consider the problem in basic terms. The sick doctor-alcoholic, drug addicted, physically ill-is rarely, if ever, going to recognise his unfitness to practise or do anything about it. If he is a GP the people most likely to recognise that all is not well are his spouse, his family, or those with whom he is associated in his work. If he is in hospital practice it may be any of his colleagues or members of the non-medical staff, or, again his family. What can be done or said to encourage such people to understand where their duty lies? It is a gravely misguided loyalty which persuades the witness of an occasion on which a doctor is clearly incapable of carrying out his duty to remain inactive; to witness other such occasions, still in silence, is little less blameworthy than to be directly responsible for them. Yet over and over again when a doctor's unfitness to practise can no longer be hidden and the truth is out, it becomes apparent that there have been those fully aware of what has been happening who have nevertheless failed to intervene. What stops them? The instinctive loyalty of a relative or colleague, the distaste for acting as an informer, the fear that the sick man's financial security may be endangered and that of his dependants? Can any such excuses justify a silence which may easily have results as disastrous as thrusting yet another Scotch - "for the road"-into the hand of someone who is already clearly unfit to drive?

I wish that Dr Allibone had indicated what he has in mind when, in the final sentence of his letter, he speaks of "the development of practical measures of help." Should every doctor over a certain age be required to submit a confidential medical report every few years from his own adviser or his colleagues or both, and submit to an independent examination if this is considered necessary? We submit our aging cars to just such a test-why not ourselves? For those who become unfit to practise before they are entitled to a full pension the existing scheme is barely adequate; perhaps this could and should be improved. I hope most sincerely that this problem, which is in fact of far greater significance and size than most people realise, will indeed receive the "proper discussion" for which Dr Allibone asks, and that out of it will emerge something practical in addition to the more humane idea. which the Health Committee represents.

\section{Bury St Edmunds,}

Douglas RoBB

Surfolk

\section{Dental surgeons without medical qualifications}

SiR,-A recent article ${ }^{1}$ in the Annals of the Royal College of Surgeons has suggested that dental surgeons should take over the primary care of patients with intraoral cancer. I believe that only about $50 \%$ of consultant dental surgeons in this country have medical qualifications in addition to dental qualifications. It may well be, therefore, that there are at present dental surgeons dealing with major cancer ablations, including block dissections and reconstructions, without formal training in surgery and without the specialist training that would be expected of a medically qualified surgeon working at consultant level.

If a patient has a malignant disease and is advised in a National Health Service department of oral or maxillofacial surgery that major ablative surgery for cancer is required, is that patient not entitled to assume that his surgeon has received the appropriate training and passed the appropriate examinations Whatever the strict legal position may be, ar health authorities justified in allowing treatment of this kind to be provided by staff whose medical training cannot be considered adequate? And what would be the answer to any complaint by a patient alleging negligence?

St Thomas's Hospital

Peter Davis

' Rapidis AD, Angelopolous AP, Langdon JD. Ann R
Coll Surg Engl 1980;62:116-8.

\section{Cutting the cost of the National Health} Service

SIR,-May I be allowed to reply to the letter of Dr P V Scott (21 June p 1535) in which it is stated that the cost to the NHS of a drug dispensed by a retail pharmacy is at least twice that in a hospital pharmacy? The evidence that I have obtained so far indicates that there is no significant difference in cost. Although the ingredient cost in a hospital pharmacy may be less, overheads are higher and these have to be paid for and taken into consideration.

Certainly my own district management team, and I expect many others, would be delighted to learn how their drug bill could be reduced by more than half. The development potential would be enormous. In those districts severely affected by the RAWP formula the need to close wards and hospitals would be obviated.

May we see evidence to support this statement published?' It is of fundamental importance to the future funding of the NHS

N G M LEgG

Health Centre,
Norwich NR2 $4 \mathrm{JL}$
The Flowers Report and the Institute of Dermatology

SIR, - The closure of the Institute of Dermatology would be the death knell of British dermatology as we know it, and of its hitherto important influence on the international affairs of the specialty. The Institute of Dermatology and its associated postgraduate hospital (St John's Hospital for Diseases of the Skin) are inseparable, their symbiotic relationship being of inestimable importance in the training of dermatologists, in research, and in its function as a referral centre. It is futile to argue that the closure of the institute (and ultimately St John's) would lead to continuation of the work at other centres. The institute together with St John's is the only centre with the critical mass necessary to engender academic excellence, with departments of high renown able to perform their functions in research, teaching, and service at the highest level. It is also able to attract scientists of the highest calibre.

I have been associated with the institute and St John's for eight and a half years. The first four and a half years were spent in London teaching hospitals, with St John's acting as the the central focus for training. This especially applied to histopathology, contact dermatitis, mycology, microbiology, and photobiology. The Saturday morning clinical meetings are world renowned. The last four years were spent as a consultant and senior lecturer. The symbiotic relationship between the institute and hospital were most impressive, allowing clinicians to be significantly involved in academic work.

The institute could not be moved outside London without losing its importance as a training and referral centre. It continues to contribute substantially to dermatology both nationally and internationally. Some of the greatest advances in the specialty have emanated from it and it has set standards of quality in research and treatment which bear comparison with those of similar institutions anywhere in the world. Its destruction would lead to incalculable loss to the very high prestige that dermatology holds in Britain, and also to the inevitable decline in research into skin diseases, and a decline in training standards and so ultimately in clinical service -all at a time when dermatology is in the ascendant. It is to be hoped that no one would wish to preside over such an ignoble act.

Royal Devon and Exeter Hospital,

Royal Devon and
Exeter EX2 5DW

\section{A computer in every surgery?}

SIR,-I believe that your leading article (28 June, $p$ 1556) gives a misleading impression that the Computer Working Party is advocating the introduction of computerisation of general practice records with unqualified enthusiasm. We are certainly enthusiastic about the potentialities of such a change, but we are well aware of the problems involved.

Perhaps a few quotations from the report will convince you and your readers of the injustice of your charge that we enter no caveats to our proposals. "... The widespread introduction of sophisticated computer systems into general practice requires the resolution of medical, economic and political problems, 